\title{
Comparative study of various glomerular filtration rate estimating equations in Egyptian patients with hepatitis $C$ virus- related liver cirrhosis: a single-center observational study
}

Mona Abd El-Rahman Abu El-Makarem', Mahmoud Mohamed Mousa ${ }^{2}$, Lion Azer Ayaad ${ }^{1}$ and Hesham K. H. Keryakos ${ }^{1 *}$ (D)

\begin{abstract}
Background: Accurate assessment of GFR is critical in patients with chronic liver disease for early detection of renal disease. Cystatin $C$ is a marker of GFR that seems to be more accurate than creatinine. The aim of the study is to assess of the performance of creatinine and cystatin C-based GFR equations in Egyptian patients with hepatitis C virus ( $\mathrm{HCV}$ )-related liver cirrhosis as compared to measured creatinine clearance. GFR was estimated using five equations; three that were based on serum creatinine, another that was based on serum cystatin $C$, and a third that was based on both in 120 patients with HCV-related liver cirrhosis as well as 60 age- and sex-matched healthy controls. The bias, precision, and accuracy of each equation were determined as compared to measured creatinine clearance using the traditional equation $U^{*} V / P$.

Results: The mean measured creatinine clearance was $51.39 \pm 16.05 \mathrm{ml} / \mathrm{min}$ per $1.73 \mathrm{~m}^{2}$. The CKD-EPI creatininecystatin C equation had the greatest precision $\left(7.5 \mathrm{ml} / \mathrm{min}\right.$ per $1.73 \mathrm{~m}^{2}$ ), and highest accuracy (68 and $93 \%$ within $10 \%$ and $30 \%$ of measured GFR, respectively), but not the lowest bias $\left(5.4 \mathrm{ml} / \mathrm{min}\right.$ per $\left.1.73 \mathrm{~m}^{2}\right)$. The CKD-EPI creatinine-cystatin C equation remained accurate even in both males (69 and 90\% within 10\% and 30\% of measured GFR, respectively) and females (68 and $97 \%$ within 10\% and 30\% of measured GFR, respectively). The CKD-EPI creatinine-cystatin C equation remained accurate even when the measured GFR was $\geq 60 \mathrm{ml} / \mathrm{min}$ per 1.73 $\mathrm{m}^{2}$ (60 and $90 \%$ within $10 \%$ and $30 \%$ of measured GFR, respectively with precision $10.5 \mathrm{ml} / \mathrm{min}$ per $1.73 \mathrm{~m}^{2}$ ).

Conclusion: CKD-EPI creatinine-cystatin C equation is more accurate at predicting GFR in HCV-related liver cirrhosis than creatinine- and cystatin- $C$ alone based equations.
\end{abstract}

Keywords: Cystatin C, Liver cirrhosis, Estimated glomerular filtration rate, Renal dysfunction

\footnotetext{
* Correspondence: hesham.keryakos@mu.edu.eg

'Department of Internal Medicine and Nephrology, Faculty of Medicine, Minia University Hospital, Aswan-Cairo Agricultural Road, El-Minya 61111,

Egypt

Full list of author information is available at the end of the article
}

() The Author(s). 2021 Open Access This article is licensed under a Creative Commons Attribution 4.0 International License, which permits use, sharing, adaptation, distribution and reproduction in any medium or format, as long as you give appropriate credit to the original author(s) and the source, provide a link to the Creative Commons licence, and indicate if changes were made. The images or other third party material in this article are included in the article's Creative Commons licence, unless indicated otherwise in a credit line to the material. If material is not included in the article's Creative Commons licence and your intended use is not permitted by statutory regulation or exceeds the permitted use, you will need to obtain permission directly from the copyright holder. To view a copy of this licence, visit http://creativecommons.org/licenses/by/4.0/. 


\section{Background}

Renal dysfunction is one of the common complications in patients with chronic liver disease with dismal impact on the patients' survival [1]. The incidence of renal dysfunction increases with the advancement of liver cirrhosis and the worsening in portal hypertension [2]. Serum creatinine is included in the Model for End Stage Liver Disease (MELD) Score, which is currently used for assessment of severity of liver disease and prioritization for liver transplantation which reflects the pivotal prognostic role of renal function in cirrhosis [3]. There is an urgent need for early and precise detection of impaired glomerular filtration rate (GFR) in cirrhotic patients, especially in those suffering from acute on chronic liver failure (ACLF) and being evaluated for liver transplantation, and in patients with refractory hepatic encephalopathy.

GFR is largely accepted as the best overall index of renal function. The GFR cannot be measured directly but can be assessed from the measured clearance of exogenous and endogenous filtration markers of which creatinine and cystatin $\mathrm{C}$ are the most commonly used. The 2012 Kidney Disease Improving Global Outcomes (KDIGO) guidelines recommend eGFR for routine evaluation of GFR and support the use of serum cystatin $\mathrm{C}$ in estimating GFR in situations where serum creatinine is unreliable. Measured GFR (mGFR) is recommended as a confirmatory test when more accuracy is needed [4].

Serum creatinine concentration is affected by several factors other than GFR, and different laboratories use different methods for measurement of serum creatinine which make results difficult to compare. Creatinine is a by-product of muscle metabolism in which creatine in the muscle is converted nonenzymatically to creatinine. Synthesis of creatinine from creatine is not constant since it is affected by the daily intake of protein and by muscle turnover. Using creatinine $(\mathrm{Cr})$-based methods to estimate GFR in advanced liver disease (ALD) patients has limitations for multiple reasons. Creatine production is decreased with the decline in hepatic functional capacity resulting in lower serum $\mathrm{Cr}$ levels. Patients with ALD are known to have less skeletal muscle mass, resulting in diminished creatine storage and less conversion of creatine to $\mathrm{Cr}$. All of these factors lead to a decreased serum $\mathrm{Cr}$ level in ALD patients, making $\mathrm{Cr}$ an unreliable factor in estimating GFR [5]. Also, the increase in serum creatinine is often delayed $48-72 \mathrm{~h}$ behind the onset of injury [6]. Analytical methods used to determine the serum $\mathrm{Cr}$ concentration can also result in variability in $\mathrm{Cr}$ levels. The kinetic Jaffe method is commonly used to measure serum $\mathrm{Cr}$ levels and can be interfered with by elevated serum bilirubin levels, resulting in false low Cr levels [7].
Inulin clearance, the standard method for measuring the GFR, is inappropriate for practical use because of cost and complicated 24-h urinary catheterization [8]. Radio-isotopic renal scans cost is high, and they cannot be used for repeated measurements. Creatinine clearance tends to overestimate the GFR and requires accurate urine volume measurement [9]. Creatinine-based equations for estimation of GFR, Cockcroft-Gault formula and modification of diet in renal disease (MDRD), and CKD-EPI equations are of limited value in cirrhotic patients as they overestimate the GFR as well [10].

Serum cystatin $\mathrm{C}(\mathrm{Cys} C)$ is a low molecular weight protein $(12.8 \mathrm{kDa})$ that functions as an extracellular cysteine protease inhibitor that has a constant rate of production and is freely filtered across renal glomeruli. However, it is completely reabsorbed and metabolized by the proximal tubular cells without secretion [11]. Several studies suggested that serum cystatin $C$ is a better alternative to serum creatinine, with constant rate of production and fewer non-GFR determinants independent of GFR, despite they are frequently present in patients with cirrhosis such as elevated CRP or low serum albumin levels. Recent findings suggest that GFR may be more effectively estimated using cystatin $C$ as a supplement or replacement for serum creatinine [12]. In the general population, serum cystatin $\mathrm{C}$ shows stronger associations than serum creatinine with cardiovascular disease (CVD) and all-cause mortality [13].

We compare the bias, precision, and accuracy of different equations that estimate glomerular filtration rate based on serum creatinine, cystatin $\mathrm{C}$ and both as compared to measured creatinine clearance for the detection of kidney disease in liver cirrhosis related to HCV Egyptian patients.

\section{Methods \\ Study participants}

The study was reviewed and approved by the Minia University Faculty of Medicine Research ethics committee (Approval NO. 186: 6/2016) and was conducted in accordance with the Helsinki Declaration. Informed consent was obtained from all participants. This study was an observational hospital-based, cohort study to compare the accuracy of different glomerular filtration rate equations based on creatinine, cystatin $\mathrm{C}$, and both as valuable tools in the detection of kidney disease in liver cirrhosis related to $\mathrm{HCV}$ in Egyptian patients; with the participants being recruited from the Internal Medicine Department of Minia University hospital. The study enrolled 120 patients with hepatitis $\mathrm{C}$ virus (HCV)-related liver cirrhosis, as well as 60 age- and sex-matched healthy controls. The diagnosis of cirrhosis was based on a combination of physical examination, laboratory tests, and abdominal ultrasonography. The inclusion criterion 
was HCV-related liver cirrhosis in adult patients $>18$ years old of both genders. The exclusion criteria for patients and healthy controls were acute viral or bacterial infection, primary renal disease or hepatorenal syndrome (HRS), chronic obstructive pulmonary disease (COPD), diabetes mellitus, thyroid dysfunction, active GIT bleeding or gastrointestinal bleeding during the month before enrollment, hepatocellular carcinoma, congestive heart failure (CHF), amputation of whole or part-limb, medications use including corticosteroids, antiviral drugs, angiotensin-II receptor blockers, angiotensin-converting enzyme inhibitors, aminoglycosides, nonsteroidal antiinflammatory drugs (NSAIDs), and L-ornithine-Laspartate.

\section{Primary outcome measures}

Percentage of estimated glomerular filtration rate values within $30 \%$ of 'true' measured glomerular filtration rate were compared. The accuracy of glomerular filtration rate (GFR) estimating equations was commonly expressed as the P30 value, the percentage of estimated GFR values within $30 \%$ of 'true' GFR. The study estimated and compared the accuracy and precision of GFR-estimating equations based on Cockcroft-Gault formula, the modification of diet in renal disease (MDRD) equation, and three Chronic Kidney Disease Epidemiology Collaboration (CKD-EPI) equations using either creatinine or cystatin $\mathrm{C}$ or a combination of both in patients with liver cirrhosis related to $\mathrm{HCV}$ expressed as the P30 value. Cockcroft-Gault Formula was calculated with the following formula: $(140-$ age $) \times$ weight $/ 72 \times$ Scr $\times 0.85$ [if female]. MDRD creatinine equation was calculated with the following formula: $175 \times$ plasma creatinine $^{-1.154} \times$ age $^{-0.203}(\times 0.742$ if female; $\times 1.21$ if black). CKD-EPI creatinine equation was calculated using the following formula: $141 \times \min (\mathrm{Scr} / \mathrm{K}, 1)^{\alpha} \times$ $\max (\mathrm{Scr} / \mathrm{K}, 1)^{-1.209} \times 0.993^{\mathrm{Age}} \times 1.018$ [if female] $\times 1.159$ [if black], where Scr is serum creatinine, $\mathrm{k}$ is 0.7 for females and 0.9 for males, ${ }^{\alpha}$ is -0.329 for females and 0.411 for males, min indicates the minimum of Scr/K or 1 , and max indicates the maximum of $\mathrm{Scr} / \mathrm{K}$ or 1 . CKDEPI cystatin $C$ equation was calculated using the following formula: $133 \times \min \left(\right.$ Scys $/ 0.8,1^{-0.499} \times \max ($ Scys $/ 0.8$, $1)^{-1.328} \times 0.996^{\text {Age }} \times 0.932$ [if female], where Scys is serum cystatin $\mathrm{C}$, min indicates the minimum of $\mathrm{Scr} / \mathrm{k}$ or 1 , and max indicates the maximum of $\mathrm{Scr} / \mathrm{k}$ or 1 . Creatinine-Cystatin $C$ equation was calculated using the following formula: $135 \times \min (\mathrm{Scr} / \mathrm{K}, 1)^{\alpha} \times \max (\mathrm{Scr} / \mathrm{K}$, $1)^{-0.601} \times \min (\text { Scys } / 0.8,1)^{-0.375} \times \max (\text { Scys } / 0.8,1)^{-0.711}$ $\times 0.995^{\text {Age }} \times 0.969$ [if female] $\times 1.08$ [if black] where Scr is serum creatinine, Scys is serum cystatin $\mathrm{C}, \mathrm{k}$ is 0.7 for females and 0.9 for males, $\alpha$ is -0.248 for females and 0.207 for males, min indicates the minimum of $\mathrm{Scr} / \mathrm{K}$ or 1 , and max indicates the maximum of $\mathrm{Scr} / \mathrm{k}$ or 1 .
Every participant was educated on proper techniques for 24-h urine collection and provided with a detailed patient education pamphlet. One day prior to visit 2, each subject completed a 24-h urine collection for timed urine creatinine clearance using the formula urine creatinine/serum creatinine multiplied by 24 -h urine volume $(\mathrm{UCr} / \mathrm{PCr}) \times \mathrm{V}$. This was divided by 1440 to get the value in $\mathrm{ml} / \mathrm{min}$.

Measurement of serum cystatin $\mathrm{C}(\mathrm{CysC})$ using a twosite second-generation enzyme-linked immunosorbent assay (ELISA) kit (Wkea Med Supplies Corp, China) was done. The microtiter plate was coated with monoclonal purified human anti-cystatin $\mathrm{C}$ antibody. Fifty microliters of standards or samples are added to the appropriate microtiter plate wells and incubate for $30 \mathrm{~min}$ at 37 ${ }^{\circ} \mathrm{C}$. Remove the liquid of each well; add $50 \mu \mathrm{l}$ of a biotinconjugated polyclonal goat anti-CysC antibody (Detection Reagent A) to each well and incubate for $30 \mathrm{~min}$ at $37{ }^{\circ} \mathrm{C}$. Aspirate each well and wash with wash buffer, repeating the process three times for a total of three washes, followed by the addition of $100 \mu \mathrm{l}$ of Avidin conjugated to horseradish peroxidase (HRP) (Detection Reagent B) to each microplate well and incubated for 1 $\mathrm{h}$ at $37^{\circ} \mathrm{C}$. Color development was achieved using a 90 $\mu \mathrm{T}$ TMB substrate solution is added to each well and incubated for $15 \mathrm{~min}$ at $37^{\circ} \mathrm{C}$. Only those wells that contain biotin-conjugated antibody and enzyme-conjugated Avidin will exhibit a change in color. The enzymesubstrate reaction is terminated by the addition of $50 \mu \mathrm{l}$ sulfuric acid solution and the color change is measured spectrophotometrically at a wavelength of $450 \pm 2 \mathrm{~nm}$. Serial dilutions of human $\mathrm{Cys} C$ were used to establish a standard curve. Laboratory measurements were performed at Clinical Pathology Laboratory at the Minia University Hospital. Assay range is $30 \mu \mathrm{g} / \mathrm{L}$ up to 800 $\mu \mathrm{g} / \mathrm{L}$ with the intra-assay CV (\%) and inter-assay CV (\%) are less than $15 \%$.

\section{Other measurements}

Demographic data, weight, height, BMI, detailed history, and thorough physical examination were obtained at enrollment. Urinalysis with microscopy was performed before the timed urine collection for GFR measurement. Complete blood count, liver function tests, renal function tests, thyroid function tests, fasting and postprandial plasma glucose, and serum alpha fetoprotein were obtained at enrollment. Complete blood count, liver function tests, urea, creatinine, and uric acid were measured using stored ethylenediaminetetraacetic acid (EDTA) plasma samples using standard techniques. $\mathrm{CBC}$ was obtained using Mindray BC-3200 auto hematology counter (Shenzhen Mindray Bio-Medical Electronics Co., Ltd. China). Serum albumin was measured using spectrophotometry. Liver function tests, urea, creatinine, and uric 
Table 1 Baseline and demographic data

\begin{tabular}{|c|c|c|c|}
\hline & HCV group $(n=120)$ & Control group $(n=60)$ & $p$ value \\
\hline \multicolumn{4}{|l|}{ Age (years) } \\
\hline Range & $(45-68)$ & $(42-72)$ & 0.274 \\
\hline Mean \pm SD & $58.05 \pm 5.91$ & $56.43 .1 \pm 7.75$ & \\
\hline \multicolumn{4}{|c|}{ Sex (frequency) } \\
\hline Male & $58(48.3 \%)$ & $30(50 \%)$ & 0.881 \\
\hline Female & $62(51.7 \%)$ & $30(50 \%)$ & \\
\hline \multicolumn{4}{|l|}{ Weight (kg) } \\
\hline Range & $(67-98)$ & $(65-95)$ & 0.239 \\
\hline Mean \pm SD & $81.5 \pm 7.31$ & $79.53 \pm 7.65$ & \\
\hline \multicolumn{4}{|l|}{ Height (cm) } \\
\hline Range & $(154-180)$ & $(155-175)$ & 0.756 \\
\hline Mean \pm SD & $164.65 \pm 6.51$ & $164.2 \pm 6.38$ & \\
\hline \multicolumn{4}{|c|}{ Body surface area $\left(\mathrm{m}^{2}\right)$} \\
\hline Range & $1.92 \pm 0.09$ & $1.9 \pm 0.1$ & 0.141 \\
\hline Mean \pm SD & $(1.69-2.09)$ & $(1.73-2.1)$ & \\
\hline \multicolumn{4}{|l|}{$\mathrm{BMI}\left(\mathrm{kg} / \mathrm{m}^{2}\right)$} \\
\hline Range & $(22.84-38.05)$ & $(24.45-35.3)$ & 0.435 \\
\hline Mean \pm SD & $30.19 \pm 3.49$ & $29.59 \pm 3.35$ & \\
\hline \multicolumn{4}{|c|}{ Serum creatinine $(\mathrm{mg} / \mathrm{dl})$} \\
\hline Range & $(0.78-2.3)$ & $(0.45-0.8)$ & $<0.001^{*}$ \\
\hline Mean \pm SD & $1.31 \pm 0.35$ & $0.64 \pm 0.1$ & \\
\hline \multicolumn{4}{|c|}{ Blood Urea (mg/dl) } \\
\hline Range & $(1.38-137.23)$ & $(18-40)$ & $<0.001^{*}$ \\
\hline Mean \pm SD & $44.83 \pm 22.06$ & $27.03 \pm 5.32$ & \\
\hline \multicolumn{4}{|c|}{ Serum cystatin C $(\mu \mathrm{g} / \mathrm{L})$} \\
\hline Range & $(0.9-4.2)$ & $(0.55-1.1)$ & $<0.001^{*}$ \\
\hline Mean \pm SD & $1.79 \pm 0.61$ & $0.72 \pm 0.11$ & \\
\hline \multicolumn{4}{|c|}{ Serum sodium (mEq/L) } \\
\hline Range & $(128-153)$ & $(134-145)$ & 0.155 \\
\hline Mean \pm SD & $138.9 \pm 4.34$ & $137.67 \pm 2.55$ & \\
\hline \multicolumn{4}{|c|}{ Serum potassium (mEq/L) } \\
\hline Range & $(3-6)$ & $(3.40-4.50)$ & $0.005^{*}$ \\
\hline Mean \pm SD & $4.06 \pm 0.47$ & $3.85 \pm 0.21$ & \\
\hline \multicolumn{4}{|c|}{ Fasting plasma glucose (mg/dl) } \\
\hline Range & $(65-110)$ & $(75-100)$ & 0.155 \\
\hline Mean \pm SD & $83.22 \pm 11.55$ & $86 \pm 6.78$ & \\
\hline \multicolumn{4}{|c|}{$2 \mathrm{~h}$ postprandial plasma glucose $(\mathrm{mg} / \mathrm{dl})$} \\
\hline Range & $(3.80-140)$ & $(96-120)$ & $0.002^{*}$ \\
\hline Mean \pm SD & $115.91 \pm 23.3$ & $105.57 \pm 6.16$ & \\
\hline \multicolumn{4}{|c|}{$\operatorname{RBCs}\left(\times 10^{6} / \mathrm{mm}^{3}\right)$} \\
\hline Range & $(2.25-5.5)$ & $(3.9-6.2)$ & $<0.001^{*}$ \\
\hline Mean \pm SD & $3.61 \pm 0.6$ & $5.17 \pm 0.59$ & \\
\hline \multicolumn{4}{|l|}{$\mathrm{HB}(\mathrm{g} / \mathrm{dl})$} \\
\hline Range & $(5.8-15.1)$ & $(8.6-15)$ & $<0.001^{*}$ \\
\hline Mean \pm SD & $9.89 \pm 1.79$ & $12.6 \pm 1.43$ & \\
\hline
\end{tabular}

aplatelets $\left(\times 10^{3} / \mathrm{mm}^{3}\right)$ 
Table 1 Baseline and demographic data (Continued)

\begin{tabular}{|c|c|c|c|}
\hline & HCV group $(n=120)$ & Control group $(n=60)$ & $p$ value \\
\hline Median & 113.5 & 330.5 & $<0.001^{*}$ \\
\hline IQR & $(92-180.5)$ & $(289-361)$ & \\
\hline \multicolumn{4}{|c|}{ WBCs $\left(\times 10^{3} / \mathrm{mm}^{3}\right)$} \\
\hline Range & $(2.90-11.2)$ & $(3.4-8.4)$ & 0.554 \\
\hline Mean \pm SD & $6.24 \pm 2.03$ & $6 \pm 1.4$ & \\
\hline \multicolumn{4}{|c|}{${ }^{\mathrm{a} T o t a l}$ bilirubin (mg/dl) } \\
\hline Median & 1.5 & 0.4 & $<0.001^{*}$ \\
\hline IQR & $(1.1-2.4)$ & $(0.3-0.4)$ & \\
\hline \multicolumn{4}{|c|}{${ }^{a}$ Direct bilirubin (mg/dl) } \\
\hline Median & 0.8 & 0.2 & $<0.001^{*}$ \\
\hline IQR & $(0.4-1)$ & $(0.2-0.3)$ & \\
\hline \multicolumn{4}{|l|}{${ }^{\mathrm{a}} \mathrm{AST}(\mathrm{IU} / \mathrm{L})$} \\
\hline Median & 54.5 & 22 & $<0.001^{*}$ \\
\hline IQR & $(39.4-84)$ & $(18-24)$ & \\
\hline \multicolumn{4}{|l|}{${ }^{\mathrm{a}} \mathrm{ALT}(\mathrm{IU} / \mathrm{L})$} \\
\hline Median & 44.5 & 23.5 & $<0.001^{*}$ \\
\hline IQR & $(32.5-67.2)$ & $(22-27)$ & \\
\hline \multicolumn{4}{|c|}{ Albumin (g/dl) } \\
\hline Range & $(1.5-4.85)$ & $(4.18-4.9)$ & $<0.001^{*}$ \\
\hline Mean \pm SD & $2.63 \pm 0.64$ & $4.56 \pm 0.24$ & \\
\hline \multicolumn{4}{|l|}{ INR } \\
\hline Range & $(1.03-2.85)$ & $(0.98-1.02)$ & $<0.001^{*}$ \\
\hline Mean \pm SD & $1.63 \pm 0.53$ & $1 \pm 0.01$ & \\
\hline \multicolumn{4}{|c|}{ Creatinine clearance $\left(\mathrm{ml} / \mathrm{min}\right.$ per $\left.1.73 \mathrm{~m}^{2}\right)$} \\
\hline Range & $(20-87.8)$ & $(85-138)$ & $<0.001^{*}$ \\
\hline Mean \pm SD & $51.39 \pm 16.05$ & $113.9 \pm 12.74$ & \\
\hline \multicolumn{4}{|c|}{ Cockcroft-Gault formula (ml/min per $1.73 \mathrm{~m}^{2}$ ) } \\
\hline Range & $(33-108)$ & $(69-202)$ & $<0.001^{*}$ \\
\hline Mean \pm SD & $70.33 \pm 20.4$ & $121.17 \pm 38.29$ & \\
\hline \multicolumn{4}{|c|}{$\operatorname{MDRD}\left(\mathrm{ml} / \mathrm{min}\right.$ per $\left.1.73 \mathrm{~m}^{2}\right)$} \\
\hline Range & $(25-98)$ & $(88-225)$ & $<0.001^{*}$ \\
\hline Mean \pm SD & $52.78 \pm 15.84$ & $126.83 \pm 29.14$ & \\
\hline \multicolumn{4}{|c|}{ CKD-EPI (ml/min per $\left.1.73 \mathrm{~m}^{2}\right)$} \\
\hline Range & $(26-95)$ & $(103-155)$ & $<0.001^{*}$ \\
\hline Mean \pm SD & $56.1 \pm 17.24$ & $121.4 \pm 12.04$ & \\
\hline \multicolumn{4}{|c|}{ CKD-EPI creatinine-cystatin C (ml/min per $\left.1.73 \mathrm{~m}^{2}\right)$} \\
\hline Range & $(16-79)$ & $(97-161)$ & $<0.001^{*}$ \\
\hline Mean \pm SD & $45.95 \pm 14.82$ & $123.77 \pm 14.52$ & \\
\hline \multicolumn{4}{|c|}{ CKD-EPI cystatin C (ml/min per $\left.1.73 \mathrm{~m}^{2}\right)$} \\
\hline Range & $(11-87)$ & $(78-164)$ & $<0.001^{*}$ \\
\hline Mean \pm SD & $40.55 \pm 16.68$ & $119.57 \pm 16.86$ & \\
\hline
\end{tabular}

Independent sample $t$ test for parametric quantitative data between the two groups

*Significant difference at $p$ value $<0.05$

${ }^{\mathrm{a}}$ Mann-Whitney test for non-parametric quantitative data between the two groups. Chi square test for qualitative data between the two groups 
acid were measured using Dimension ES chemical autoanalyzer (Dade Behring, Marburg, Germany).

Serological tests for hepatitis virus B and $C$ were done. Anti-HCV antibodies by enzyme-linked immunosorbent assay (ELISA) and detectable serum HCV-RNA by polymerase chain reaction for 6 months or more were needed to confirm the diagnosis of $\mathrm{HCV}$ infection. Abdominal ultrasound was done for all patients.

\section{Statistical analysis}

All statistical analyses were performed with Statistical Package for the Social Science (SPSS for windows version 25.0) (SPSS Inc., Tokyo, Japan). The continuous variables were expressed as mean \pm SD which compared using chi square test. Pearson's correlation coefficient was used to estimate the correlation between each two variables. Statistical significance was defined as a probability level of $p<0.05$. Bias was defined as the mean difference between measured and estimated GFR; precision was defined as the SD of the difference between measured and estimated GFR. Both precision and bias were expressed as $\mathrm{ml} / \mathrm{min}$ per $1.73 \mathrm{~m}^{2}$; accuracy was defined as the proportion of values that were within 10 or $30 \%$ of the measured GFR.

\section{Results}

A total of 120 patients with hepatitis $\mathrm{C}$ virus (HCV)-related liver cirrhosis who met the inclusion criteria and 60 healthy volunteers as a control group were included in this observational hospital-based, cohort study. The baseline characteristics of the cohort are presented in Table 1. Both groups are age- and sex-matched (58.05 \pm 5.91 years vs. $56.43 .1 \pm 7.75$ years; $p=0.274$ ). There were 62 females and 58 male patients in the HCV group compared to 30 females and 30 males in the control group. The mean measured GFR in HCV patients using measured creatinine clearance was $51.39 \pm 16.05 \mathrm{ml} / \mathrm{min}$ per $1.73 \mathrm{~m}^{2}$ with a range of $20-87.8 \mathrm{ml} / \mathrm{min}$ per 1.73 $\mathrm{m}^{2}$.

\section{Correlation of eGFR formulas with mGFR}

There was significant positive correlation between the measured creatinine clearance and estimated GFR formulas in HCV group Table 2.

\section{Simple linear regression analysis}

As regarding simple regression analysis, each GFR formula had a significant regression model for predicting the GFR (measured creatinine clearance is the reference model). The most predictive one is CKD-EPI creatininecystatin C equation $\left(R^{2}=0.785\right)$, then CKD-EPI Cystatin $\mathrm{C}$ equation $\left(R^{2}=0.657\right)$ (Table 3$)$.
Table 2 Correlation between measured creatinine clearance and estimated GFR equations in HCV group

\begin{tabular}{lll}
\hline HCV group $(\boldsymbol{n}=\mathbf{1 2 0})$ & \multicolumn{2}{l}{ Creatinine clearance } \\
\cline { 2 - 3 } & $\boldsymbol{r}$ & $\boldsymbol{p}$ value \\
\hline Cockcroft-Gault & 0.629 & $<0.001^{*}$ \\
MDRD & 0.661 & $<0.001^{*}$ \\
CKD-EPI & 0.685 & $<0.001^{*}$ \\
CKD-EPI creatinine-Cystatin C & 0.886 & $<0.001^{*}$ \\
CKD-EPI cystatin C & 0.811 & $<0.001^{*}$ \\
\hline
\end{tabular}

Pearson's correlation coefficient

*Significant correlation at $p$ value $<0.05$

\section{Multiple stepwise regression analysis}

To improve the accuracy of prediction of GFR from different equations, multiple stepwise regression analysis was used. The most predictive model is CKD-EPI creatinine-cystatin C $\left(R^{2}=0.785\right)$ (Table 4$)$.

\section{Bias, precision, and accuracy of estimated GFR}

The performance of the various estimates of GFR is shown in Table 5 and Fig. 1. The MDRD equation had the least bias $\left(-1.4 \mathrm{ml} / \mathrm{min}\right.$ per $\left.1.73 \mathrm{~m}^{2}\right)$. Meanwhile, CKD-EPI creatinine-cystatin $\mathrm{C}$ equation had the best precision $\left(7.5 \mathrm{ml} / \mathrm{min}\right.$ per $\left.1.73 \mathrm{~m}^{2}\right)$ the highest percentage of values that fell within $30 \%$ of the measured GFR (93\%). In addition, $68 \%$ of GFR estimates fell within $10 \%$ of the measured GFR.

\section{Performance of the derived mathematical equations according to sex}

The performance of the various estimates of GFR in male patients of the HCV study group $(n=29)$ is shown in Table 6. The MDRD equation had the least bias $\left(-4 \mathrm{ml} / \mathrm{min}\right.$ per $\left.1.73 \mathrm{~m}^{2}\right)$. Meanwhile, CKD-EPI creatinine-cystatin $\mathrm{C}$ equation had the best precision $\left(8.5 \mathrm{ml} / \mathrm{min}\right.$ per $\left.1.73 \mathrm{~m}^{2}\right)$, the highest percentage of values that fell within $30 \%$ of the measured GFR (90\%). In addition, 69\% of GFR estimates fell within $10 \%$ of the measured GFR.

The performance of the various estimates of GFR in female patients of the HCV study group $(n=31)$ is shown in Table 7. The MDRD equation had the least bias $\left(1 \mathrm{ml} / \mathrm{min}\right.$ per $\left.1.73 \mathrm{~m}^{2}\right)$. Meanwhile, CKD-EPI creatinine-cystatin $\mathrm{C}$ equation had the best precision $\left(6.5 \mathrm{ml} / \mathrm{min}\right.$ per $\left.1.73 \mathrm{~m}^{2}\right)$, the highest percentage of values that fell within $30 \%$ of the measured GFR (97\%). In addition, $68 \%$ of GFR estimates fell within $10 \%$ of the measured GFR.

Performance of the derived mathematical equations in patients with GFR above and below $60 \mathrm{ml} / \mathrm{min} / 1.73 \mathrm{~m}^{2}$ The performance of the various estimates of GFR in patients of the HCV study group GFR $\geq 60 \mathrm{ml} / \mathrm{min}$ per 
Table 3 Simple linear regression analysis for determine prediction of creatinine clearance by different GFR formulas

\begin{tabular}{|c|c|c|c|c|c|}
\hline \multirow[t]{2}{*}{ Model } & \multicolumn{2}{|c|}{ Unstandardized coefficients } & \multirow[t]{2}{*}{$p$ value } & \multirow[t]{2}{*}{$R$} & \multirow[t]{2}{*}{$R^{2}$} \\
\hline & $B$ & Std. error & & & \\
\hline Constant & 16.57 & 5.88 & $0.007^{*}$ & 0.629 & 0.396 \\
\hline Cockcroft-Gault & 0.5 & 0.08 & $<0.001^{*}$ & & \\
\hline Constant & 16.07 & 5.5 & $0.005^{*}$ & 0.661 & 0.436 \\
\hline MDRD & 0.67 & 0.1 & $<0.001^{*}$ & & \\
\hline Constant & 15.63 & 5.23 & 0.004 & 0.685 & 0.469 \\
\hline CKD-EPI & 0.64 & 0.09 & $<0.001^{*}$ & & \\
\hline Constant & 7.29 & 3.18 & $0.026^{*}$ & 0.886 & 0.785 \\
\hline CKD-EPI creatinine-cystatin C & 0.96 & 0.07 & $<0.001^{*}$ & & \\
\hline Constant & 19.76 & 3.24 & $<0.001^{*}$ & 0.811 & 0.657 \\
\hline CKD-EPI cystatin C & 0.78 & 0.07 & $<0.001^{*}$ & & \\
\hline
\end{tabular}

$1.73 \mathrm{~m}^{2}(n=20)$ is shown in Table 8 . The CKD-EPI equation had the least bias $\left(-1.1 \mathrm{ml} / \mathrm{min}\right.$ per $\left.1.73 \mathrm{~m}^{2}\right)$. Meanwhile, CKD-EPI creatinine cystatin- $C$ equation had the best precision $\left(10.5 \mathrm{ml} / \mathrm{min}\right.$ per $\left.1.73 \mathrm{~m}^{2}\right)$, the highest percentage of values that fell within $30 \%$ of the measured GFR (90\%). In addition, $60 \%$ of GFR estimates fell within $10 \%$ of the measured GFR.

The performance of the various estimates of GFR in patients of the HCV study group GFR $<60 \mathrm{ml} / \mathrm{min}$ per $1.73 \mathrm{~m}^{2}(n=40)$ is shown in Table 9. Both MDRD and CKD-EPI creatinine-cystatin $C$ equation had the least bias $\left(-4.1 \mathrm{ml} / \mathrm{min}\right.$ per $1.73 \mathrm{~m}^{2}$ and $4.1 \mathrm{ml} / \mathrm{min}$ per 1.73 $\mathrm{m}^{2}$ respectively). Meanwhile, CKD-EPI creatininecystatin $C$ equation had the best precision $(5 \mathrm{ml} / \mathrm{min}$ per $1.73 \mathrm{~m}^{2}$ ), the highest percentage of values that fell within $30 \%$ of the measured GFR (95\%). In addition, $73 \%$ of GFR estimates fell within $10 \%$ of the measured GFR.

\section{Discussion}

Our cross-sectional observational study has demonstrated that eGFR using CKD-EPI creatinine-cystatin C equation (eGFRcr-cys) provide results comparable to those measured by creatinine clearance with the best performance; meanwhile, creatinine and cystatin Cbased equations were inaccurate for the assessment of renal function in cirrhotic patients. All methods of estimation of GFR have limitations in patients with liver cirrhosis with $\mathrm{Cr}$-based equations tend to overestimate

Table 4 Multiple stepwise linear regression analysis for determine the GFR formulas predicting the creatinine clearance revealed this model

\begin{tabular}{|c|c|c|c|c|c|}
\hline \multirow[t]{2}{*}{ Model } & \multicolumn{2}{|c|}{$\begin{array}{l}\text { Unstandardized } \\
\text { coefficients }\end{array}$} & \multirow[t]{2}{*}{$P$ value } & \multirow[t]{2}{*}{$R$} & \multirow[t]{2}{*}{$R^{2}$} \\
\hline & $B$ & Std. error & & & \\
\hline Constant & 7.29 & 3.18 & $0.026^{*}$ & 0.886 & 0.785 \\
\hline CKD-EPI creatinine-cystatin C & 0.96 & 0.07 & $<0.001^{*}$ & & \\
\hline
\end{tabular}

mGFR, and CysC-based equations tend to underestimate mGFR. This is in accordance with a previous study that highlight the potential risk of unnecessary simultaneous liver and kidney transplantation in patients with endstage liver disease with the use of CysC-based equations with consequent underestimation of GFR [14]. In a single-center cross-sectional study to assess the accuracy of creatinine or cystatin C-based equations to estimate kidney function in orthotopic liver transplant (OLT) recipients, neither serum creatinine nor cystatin $\mathrm{C}$ were good predictors of GFR in cirrhotic patients, even after stratification for Child-Pugh-Turcot (CPT) score, gender, and BMI [15].

Population diversity may play a role in the performance of the eGFR equations. This is suggested by a cross-sectional analysis from the eGFR of 654 indigenous Australians known to be at high risk of end-stage kidney disease (ESKD) that showed that CysC-based eGFR equations may not perform well in populations with high levels of chronic inflammation. CKD-EPI eGFR based on serum creatinine remains the preferred equation in indigenous Australians [16].

Table 5 Bias, precision, and accuracy of creatinine and cystatin C estimates in HCV study group $(n=120)$

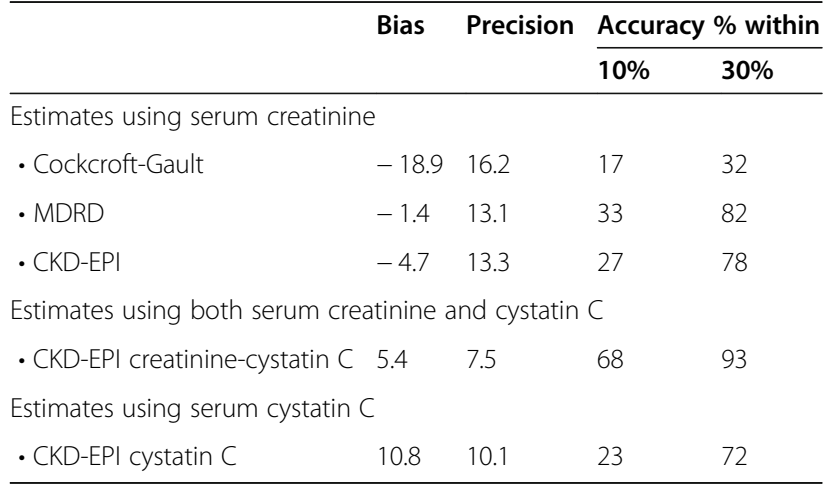



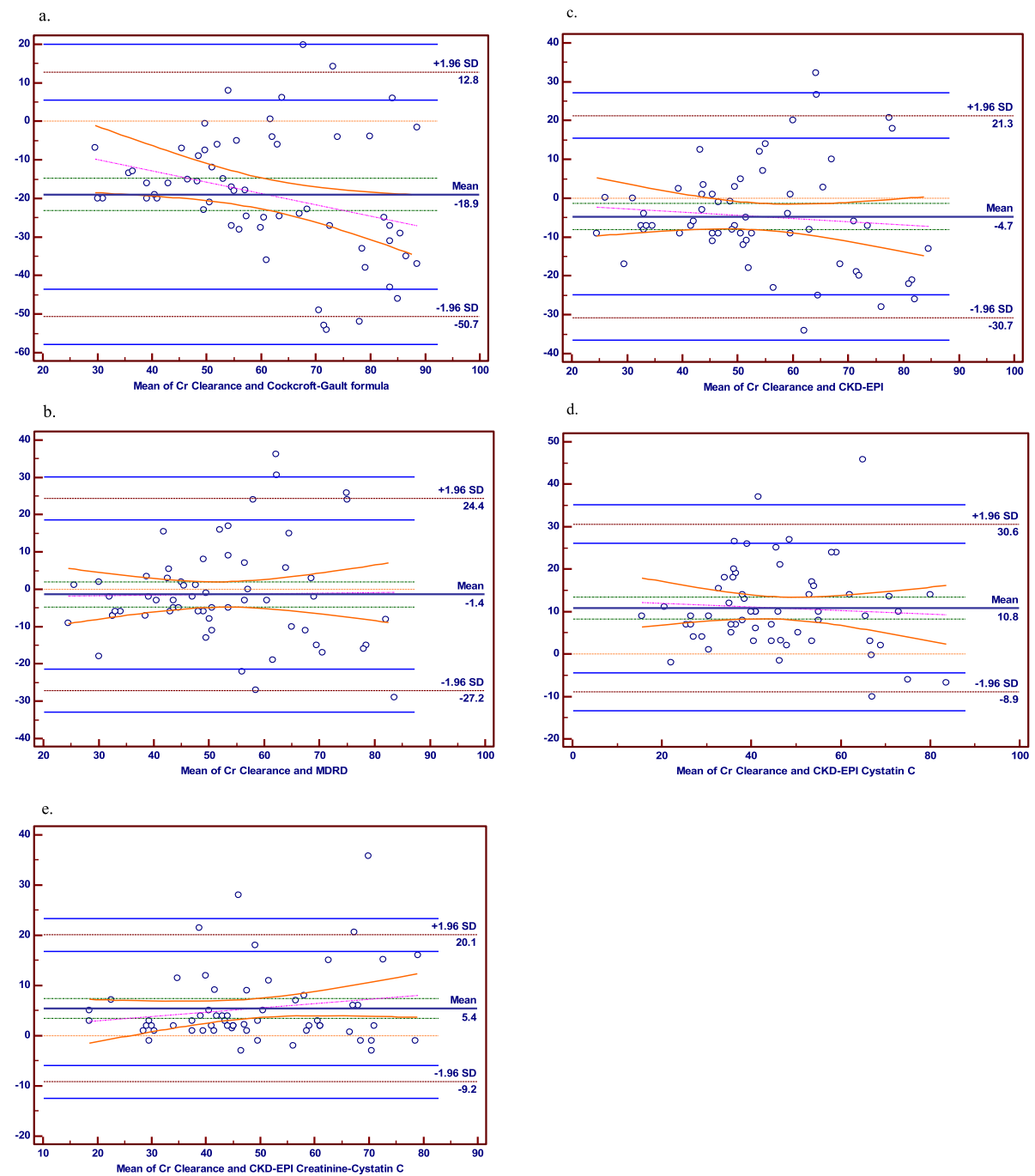

Fig. 1 Bland Altman plots to assess the agreement between measured creatinine clearance and different eGFR formulas. a Cockcroft-Gault formula. b MDRD formula figure. c CKD-EPI formula. d CKD-EPI cystatin C formula. e CKD-EPI creatinine-cystatin C formula

Table 6 Bias, precision, and accuracy of creatinine and cystatin C estimates in male patients

\begin{tabular}{|c|c|c|c|c|}
\hline & \multirow[t]{2}{*}{ Bias } & \multirow[t]{2}{*}{ Precision } & \multicolumn{2}{|c|}{ Accuracy \% within } \\
\hline & & & $10 \%$ & $30 \%$ \\
\hline \multicolumn{5}{|l|}{ Estimates using serum creatinine } \\
\hline - Cockcroft-Gault & -20.2 & 14.7 & 17 & 24 \\
\hline - MDRD & -4 & 10.7 & 24 & 90 \\
\hline - CKD-EPI & -6.8 & 10.7 & 24 & 86 \\
\hline \multicolumn{5}{|c|}{ Estimates using both serum creatinine and cystatin $C$} \\
\hline - CKD-EPI creatinine-cystatin C equation & 6 & 8.5 & 69 & 90 \\
\hline \multicolumn{5}{|l|}{ Estimates using serum cystatin $C$} \\
\hline - CKD-EPI cystatin C equation & 14.2 & 10.6 & 10 & 66 \\
\hline
\end{tabular}


Table 7 Bias, precision, and accuracy of creatinine and cystatin C estimates in female patients

\begin{tabular}{|c|c|c|c|c|}
\hline & \multirow[t]{2}{*}{ Bias } & \multirow[t]{2}{*}{ Precision } & \multicolumn{2}{|c|}{ Accuracy $\%$ within } \\
\hline & & & $10 \%$ & $30 \%$ \\
\hline \multicolumn{5}{|l|}{ Estimates using serum creatinine } \\
\hline - Cockcroft-Gault & -17.8 & 17.6 & 16 & 39 \\
\hline$\cdot$ MDRD & 1 & 14.8 & 42 & 74 \\
\hline$\cdot$ CKD-EPI & -2.8 & 15.2 & 29 & 71 \\
\hline \multicolumn{5}{|c|}{ Estimates using both serum creatinine and cystatin C } \\
\hline - CKD-EPI creatinine cystatin C & 4.9 & 6.5 & 68 & 97 \\
\hline \multicolumn{5}{|l|}{ Estimates using serum cystatin C } \\
\hline - CKD-EPI cystatin C & 7.7 & 8.6 & 35 & 77 \\
\hline
\end{tabular}

In our study, we have found that all eGFR formulae were positively correlated with mGFR with the most predictive formula being eGFRcr-cys using both simple and multiple stepwise regression analyses. We tested the performance of the different equations in our cohort of Egyptian patients, and we found that MDRD had the least bias but eGFRcr-cys had the best precision and accuracy within both $10 \%$ and $30 \%$. Then we tested the influence of sex on the performance of different equations. We found the same previous results in both male and female patients excluding any influence of sex. Then we tested the performance of the equations in patients with measured GFR $\geq 60$ or $<60 \mathrm{ml} / \mathrm{min} / \mathrm{m} 2$, and we found CKDEPI equation had the least bias with eGFRcr-cys had the best precision and accuracy in patients with GFR $\geq 60 \mathrm{ml} / \mathrm{min} / \mathrm{m}^{2}$, but with GFR $<60 \mathrm{ml} / \mathrm{min} / \mathrm{m}^{2}$ eGFRcr-cys had the least bias together with MDRD but with better precision and accuracy.

Our results agree with a study published by Adachi et al. 2015 in Japanese population who assessed the performance of GFR equations compared with inulin clearance as a gold standard in 14 patients with cirrhosis.

Table 8 Bias, precision, and accuracy of creatinine and cystatin $C$ estimates for patients with estimated $\geq 60 \mathrm{ml} / \mathrm{min}$ per 1.73 $\mathrm{m}^{2}(n=20)$

\begin{tabular}{lcccc}
\hline & Bias & Precision & \multicolumn{2}{l}{ Accuracy \% within } \\
\cline { 4 - 5 } & & & $\mathbf{1 0 \%}$ & $\mathbf{3 0 \%}$ \\
\hline Estimates using serum creatinine & & & \\
- Cockcroft-Gault & -15.8 & 20.5 & 40 & 50 \\
- MDRD & 4.1 & 18.8 & 15 & 80 \\
- CKD-EPI & -1.1 & 19.2 & 20 & 65 \\
Estimates using both serum creatinine and cystatin C & \\
- CKD-EPI creatinine cystatin C & 8.2 & 10.5 & 60 & 90 \\
Estimates using serum cystatin C & \multicolumn{3}{c}{} \\
- CKD-EPI cystatin C & 12.9 & 14.2 & 25 & 75 \\
\hline
\end{tabular}

Table 9 Bias, precision, and accuracy of creatinine and cystatin $C$ estimates for patients with estimated $<60 \mathrm{ml} / \mathrm{min}$ per 1.73 $\mathrm{m}^{2}(n=20)$

\begin{tabular}{lllll}
\hline & Bias & Precision & \multicolumn{2}{l}{ Accuracy \% within } \\
\cline { 4 - 5 } & & & $\mathbf{1 0 \%}$ & $\mathbf{3 0 \%}$ \\
\hline Estimates using serum creatinine & & & \\
- Cockcroft-Gault & -20.5 & 13.6 & 5 & 23 \\
- MDRD & -4.1 & 8.1 & 43 & 83 \\
- CKD-EPI & -6.5 & 8.7 & 30 & 85 \\
Estimates using both serum creatinine and cystatin C & \\
- CKD-EPI creatinine cystatin C & 4.1 & 5 & 73 & 95 \\
Estimates using serum cystatin C & \multicolumn{5}{l}{} \\
- CKD-EPI cystatin C & 9.8 & 7.3 & 23 & 70 \\
\hline
\end{tabular}

They found that eGFRcys was more accurate than Crbased eGFR in estimating renal function in cirrhotic patients. Moreover, they found that CysC-based eGFR and not creatinine-based eGFR equations, along with albumin, Child-Pugh grade, and the presence of hepatocellular carcinoma, was independently associated with overall survival in 49 cirrhotic patients [17]. Another study evaluated serum $\mathrm{Cys} C$ in 70 Egyptian patients who were potential candidates for living donor liver transplantation with serum creatinine $<1.5 \mathrm{mg} / \mathrm{dl}$, as a marker of early renal impairment (GFR of $60-89 \mathrm{ml} / \mathrm{min} / 1.73 \mathrm{~m}^{2}$ ). They found that $\mathrm{CysC}$ and $\mathrm{CysC}$-based equations had the highest significant correlation to GFR as measured by ${ }^{99 \mathrm{~m}}$ Tc-DTPA renal scan [18].

Another study from Germany conducted on ninety-seven in hospital patients with cirrhosis and $24-\mathrm{h}$ creatinine clearance of at least $40 \mathrm{ml} / \mathrm{min}$ to assess the value of serum $\mathrm{CysC}$ concentration in the detection of moderately impaired renal function. They found that serum $\mathrm{CysC}$ is a valuable marker for early diagnosis of moderately impaired renal function in patients with cirrhosis especially in female patients or with child-Pugh class $\mathrm{C}$ with high diagnostic sensitivity ( $77.8 \%$ and $86.7 \%$ respectively), greater than $\mathrm{sCr}(38.9 \%$ and $60 \%)$ [19].

A cross-sectional analysis conducted in diverse populations with 1119 participants from 5 different studies in which GFR was measured with $\mathrm{Cys} C$ and $\mathrm{Cr}$ assays were traceable to primary reference materials. The combined $\mathrm{Cr}-\mathrm{Cys} \mathrm{C}$ equation had been shown to perform better than equations based on either of these markers alone at different GFR and may be useful as a confirmatory test for chronic kidney disease [20].

Our cross-sectional study has some limitations. First, the sample size is relatively small and might affect the statistical power. Second, the survival correlation of the different equations is needed to be studied on a longer follow-up. 


\section{Conclusion}

In conclusion, we report that GFRcr-cys formula has the best precision and accuracy in estimating GFR in Egyptian patients with liver cirrhosis irrespective of sex or degree of mGFR. This is of utmost importance in patients with refractory hepatic encephalopathy or being evaluated for liver transplantation. Our study in addition to similar studies should spark investigations on the influence of population diversity on different eGFR equations.

\begin{abstract}
Abbreviations
GFR: Glomerular filtration rate; HCV: Hepatitis C virus; CKD-EPI: Chronic kidney disease-epidemiology collaboration; MDRD: Modification of diet in renal disease; MELD: Model for end-stage liver disease; ACLF: Acute on chronic liver failure; KDIGO: Kidney Disease Improving Global Outcomes; mGFR: Measured glomerular filtration rate; Cr: Creatinine; ALD: Advanced liver disease; CysC: Cystatin C; CRP: C-reactive protein; CVD: Cardiovascular disease; BMI: Body mass index
\end{abstract}

\section{Acknowledgements}

We thank our colleagues from Internal Medicine department who provided insight and expertise that greatly assisted the research.

\section{Authors' contributions}

MAAM and HKHK equally contributed to the conception and design of the research; MMM contributed to the design of the research and laboratory work; LAA contributed to the acquisition and analysis of the data; MAAM and MMM contributed to the interpretation of data; and HKHK drafted the manuscript. All authors critically revised the manuscript, agree to be fully accountable for ensuring the integrity and accuracy of the work, and read and approved the final manuscript.

\section{Funding}

Funding for the laboratory kits was provided by Minia Faculty of Medicine.

\section{Availability of data and materials}

Available.

\section{Declarations}

\section{Ethics approval and consent to participate}

The research was conducted in accordance with the ethical standards of the Minia University committee on human experimentation and with the Helsinki Declaration of 1975, as revised in 2008. Informed written consent was obtained from all patients for being included in the study.

\section{Consent for publication}

Not applicable.

\section{Competing interests}

The authors declare that they have no competing interests.

\section{Author details}

${ }^{1}$ Department of Internal Medicine and Nephrology, Faculty of Medicine, Minia University Hospital, Aswan-Cairo Agricultural Road, El-Minya 61111, Egypt. ${ }^{2}$ Clinical Pathology Department, Faculty of Medicine, Minia University Hospital, Minia, Egypt.

Received: 15 December 2020 Accepted: 15 March 2021 Published online: 30 March 2021

\section{References}

1. Slack A, Yeoman A, Wendon J (2010) Renal dysfunction in chronic liver disease. Crit Care 14(2):214. https://doi.org/10.1186/cc8855

2. Arroyo V, Fernandez J, Gines P (2008) Pathogenesis and treatment of hepatorenal syndrome. Semin Liver Dis 28(1):81-95. https://doi.org/10.1055/ s-2008-1040323
3. Alessandria C, Ozdogan O, Guevara M, Restuccia T, Jimenez W, Arroyo V et al (2005) MELD score and clinical type predict prognosis in hepatorenal syndrome: relevance to liver transplantation. Hepatology. 41(6):1282-1289. https://doi.org/10.1002/hep.20687

4. Stevens PE, Levin A (2013) Kidney disease: improving global outcomes chronic kidney disease guideline development work group M. Evaluation and management of chronic kidney disease: synopsis of the kidney disease: improving global outcomes 2012 clinical practice guideline. Ann Intern Med 158(11):825-830. https://doi.org/10.7326/0003-4819-158-11-201306040-00007

5. Cocchetto DM, Tschanz C, Bjornsson TD (1983) Decreased rate of creatinine production in patients with hepatic disease: implications for estimation of creatinine clearance. Ther Drug Monit 5(2):161-168. https://doi.org/10.1097/ 00007691-198306000-00002

6. Wong F, Nadim MK, Kellum JA, Salerno F, Bellomo R, Gerbes A, Angeli P, Moreau R, Davenport A, Jalan R, Ronco C, Genyk Y, Arroyo V (2011) Working party proposal for a revised classification system of renal dysfunction in patients with cirrhosis. Gut. 60(5):702-709. https://doi.org/10.1136/gut.2010.236133

7. Daugherty NA, Hammond KB, Osberg IM (1978) Bilirubin interference with the kinetic Jaffe method for serum creatinine. Clin Chem 24(2):392-393. https://doi.org/10.1093/clinchem/24.2.392

8. Cholongitas E, Marelli L, Kerry A, Senzolo M, Goodier DW, Nair D, Thomas M, Patch D, Burroughs AK (2007) Different methods of creatinine measurement significantly affect MELD scores. Liver Transpl 13(4):523-529. https://doi. org/10.1002/lt.20994

9. Proulx NL, Akbari A, Garg AX, Rostom A, Jaffey J, Clark HD (2005) Measured creatinine clearance from timed urine collections substantially overestimates glomerular filtration rate in patients with liver cirrhosis: a systematic review and individual patient meta-analysis. Nephrol Dial Transplant 20(8):16171622. https://doi.org/10.1093/ndt/gfh839

10. Beben T, Rifkin DE (2015) GFR estimating equations and liver disease. Adv Chronic Kidney Dis 22(5):337-342. https://doi.org/10.1053/j.ackd.2015.05.003

11. Porrini E, Ruggenenti P, Luis-Lima S, Carrara F, Jimenez A, de Vries APJ et al (2019) Estimated GFR: time for a critical appraisal. Nat Rev Nephrol 15(3): 177-190. https://doi.org/10.1038/s41581-018-0080-9

12. Ferguson TW, Komenda P, Tangri N (2015) Cystatin C as a biomarker for estimating glomerular filtration rate. Curr Opin Nephrol Hypertens 24(3): 295-300. https://doi.org/10.1097/MNH.0000000000000115

13. Taglieri N, Koenig W, Kaski JC (2009) Cystatin C and cardiovascular risk. Clin Chem 55(11):1932-1943. https://doi.org/10.1373/clinchem.2009.128397

14. Krones E, Fickert P, Zitta S, Neunherz S, Artinger K, Reibnegger G, Durchschein F, Wagner D, Stojakovic T, Stadlbauer V, Fauler G, Stauber R, Zollner G, Kniepeiss D, Rosenkranz AR (2015) The chronic kidney disease epidemiology collaboration equation combining creatinine and cystatin C accurately assesses renal function in patients with cirrhosis. BMC Nephrol 16(1):196. https://doi.org/10.1186/s12882-015-0188-0

15. Boudville N, Salama M, Jeffrey GP, Ferrari P (2009) The inaccuracy of cystatin $\mathrm{C}$ and creatinine-based equations in predicting GFR in orthotopic liver transplant recipients. Nephrol Dial Transplant 24(9):2926-2930. https://doi. org/10.1093/ndt/gfp255

16. Barr EL, Maple-Brown L, Barzi F, Hughes JT, Jerums G, Ekinci El et al (2017) Comparison of creatinine and cystatin C based eGFR in the estimation of glomerular filtration rate in Indigenous Australians: the eGFR Study. Clin Biochem 50(6):301-308. https://doi.org/10.1016/j.clinbiochem.2016.11.024

17. Adachi M, Tanaka A, Aiso M, Takamori Y, Takikawa H (2015) Benefit of cystatin $C$ in evaluation of renal function and prediction of survival in patients with cirrhosis. Hepatol Res 45(13):1299-1306. https://doi.org/1 0.1111/hepr.12508

18. Omar M, Abdel-Razek W, Abo-Raia G, Assem M, El-Azab G (2015) Evaluation of serum cystatin $C$ as a marker of early renal impairment in patients with liver cirrhosis. Int J Hepatol 2015:309042

19. Gerbes AL, Gulberg V, Bilzer M, Vogeser M (2002) Evaluation of serum cystatin $C$ concentration as a marker of renal function in patients with cirrhosis of the liver. Gut. 50(1):106-110. https://doi.org/10.1136/gut.50.1.106

20. Inker LA, Schmid CH, Tighiouart H, Eckfeldt JH, Feldman HI, Greene T, Kusek JW, Manzi J, van Lente F, Zhang YL, Coresh J, Levey AS, CKD-EPI Investigators (2012) Estimating glomerular filtration rate from serum creatinine and cystatin C. N Engl J Med 367(1):20-29. https://doi.org/10.1056/NEJMoa1114248

\section{Publisher's Note}

Springer Nature remains neutral with regard to jurisdictional claims in published maps and institutional affiliations. 